\title{
Responses of Two Somaclonal Variants of Quince (Cydonia oblonga) to Iron Deficiency in the Greenhouse and Field
}

\author{
Sumonthip Bunnag ${ }^{1}$ \\ Department of Horticulture, Oregon State University, Corvallis, OR 97331-7304

\begin{abstract}
Ramon Dolcet-Sanjuan
Department de Genètica Vegetal, Institut de Reçerca i Tecnologia Agroalimentaria, Centre de Cabrils, o8348 Cabrils, Barcelona, Spain
\end{abstract}

\author{
David W.S. Mok and Machteld C. Mok \\ Department of Horticulture and Center for Gene Research and Biotechnology, Oregon State University, \\ Corvallis, OR $97331-7304$
}

Additional index words. rootstock, pear, Fe chlorosis

\begin{abstract}
Somaclonal quince (Cydonia oblonga Mill.) variants IE-1 and IE-2 (Dolcet-Sanjuan et al., 1992) were more tolerant to Fe-deficient conditions in vitro than the original clone Quince A. The tolerance was evidenced by higher chlorophyll concentrations in leaves, higher Fe(III) reduction in roots, and increased acidification of the medium. In Summers 1993 and 1994, the two variants and Quince A were compared in the greenhouse, grown in normal potting soil (pH 5) and in soil obtained from an Fe-deficient orchard, with and without the addition of lime and $\mathrm{KHCO}_{3}$ solution to increase the pH (up to pH 8.3) and intensify Fe stress. In both years, the variants had significantly higher leaf chlorophyll concentrations than Quince A when grown in high-pH soils. The $\mathrm{Fe}^{+2}$ concentrations in leaves were also higher in the variants. Under field conditions at IRTA Reus, Spain, IE-1 and IE-2 had higher chlorophyll concentrations than the controls at some, but not all, analysis dates. These results suggest that IE-1 and IE-2, when grown as young plants in the greenhouse, have higher tolerance to Fe deficiency than Quince A, as observed in vitro, but that the tolerance is more variable under uncontrolled conditions in the field.
\end{abstract}

Iron is an important micronutrient required for several essential processes in plants, including photosynthesis and respiration. Many soil types, particularly those with high $\mathrm{pH}$, limit Fe availability to plants, thereby causing leaf chlorosis. There is wide variability among crops in sensitivity to low Fe; some fruit crops, most notably pear and peach, are very sensitive (Lombard and Westwood, 1987). Quince is a widely used dwarfing rootstock for pear and is particularly important in high-density orchards. However, quince uses soil Fe relatively inefficiently (Lombard and Westwood, 1987). To improve the performance of quince as a rootstock, attempts have been made to select genotypes with increased Fe use (Viti and Cinelli, 1989). Although further improvement by breeding may be attainable, it is a long-term process and requires evaluation combined with different pear scions. An alternative strategy is the application of biotechnology, such as selection of somaclonal variants with improved Fe use or transformation with genes involved in Fe uptake. Such strategies should allow improvement of established clones with proven performance, thus avoiding a lengthy selection process.

Previously, two somaclonal variants, IE-1 and IE-2, were selected from a population of about 2000 quince shoots derived from cultured leaf discs (Dolcet-Sanjuan, 1991; Dolcet-Sanjuan et al., 1992). These variants had significantly higher leaf chlorophyll

Received for publication 10 Jan. 1996. Accepted for publication 21 June 1996 Research was funded by the Oregon Agricultural Experiment Station (paper no. 10,885) and USDA Special Grant: Oregon/Massachusetts Biotechnology Partnership. Financial support for S.B. was provided by USAID. We thank T. Righetti for providing advice on soil and K. Rowe for his aid with the statistical analyses. The cost of publishing this paper was defrayed in part by the payment of page charges. Under postal regulations, this paper therefore must be hereby marked advertisement solely to indicate this fact.

${ }^{1}$ Current address: Dept. of Biology, Khon Kaen Univ., Khon Kaen 40002, Thailand. concentrations than unselected Quince A controls when grown under Fe-deficient conditions in vitro and displayed a higher ability to reduce Fe(III) and to acidify the culture medium (DolcetSanjuan et al., 1992). These traits were expressed in unrooted shoots and plantlets. In the present study we report the performance of the two variants under greenhouse conditions, in standard potting soil and soil with high $\mathrm{pH}$ and bicarbonate, and in a field nursery plot in Spain.

\section{Materials and Methods}

Plant materials. In vitro cultured shoots of Cydonia oblonga Quince A (East Malling) and two somaclonal variants, IE-1 and IE-2 (Dolcet-Sanjuan, 1991; Dolcet-Sanjuan et al., 1992), were subcultured by monthly transfers onto a micropropagation medium and rooted as described by Dolcet-Sanjuan et al. (1990). Plantlets were transferred to flats in the greenhouse (1 soil : 1 perlite mix) and placed on a misting bed. After 4 weeks, plants were transplanted to pots with soil consisting of 2 peat : 1 perlite : 1 vermiculite and Nutricote slow-release fertilizer $\left(2 \mathrm{~kg} \cdot \mathrm{m}^{-2}\right)$. Pots were placed in the greenhouse maintained at $24^{\circ} \mathrm{C}$ (day) and $18^{\circ} \mathrm{C}$ (night) under natural light conditions.

Greenhouse experiments. Two experiments were performed over 2 years. In 1993, plants were moved to the greenhouse in July, and the experiment, with four soil treatments (A-D; see below), was started on 4 Aug. Pots were arranged into four blocks, each consisting of one soil type. A block contained eight plants each of Quince A, IE-1, and IE-2, randomly arranged. Leaf samples for chlorophyll determinations were taken from each plant after 6 weeks (15 Sept.). The upper three fully expanded leaves from two plants were pooled for chlorophyll extraction.

In 1994, plants were moved to the greenhouse in March, and the 


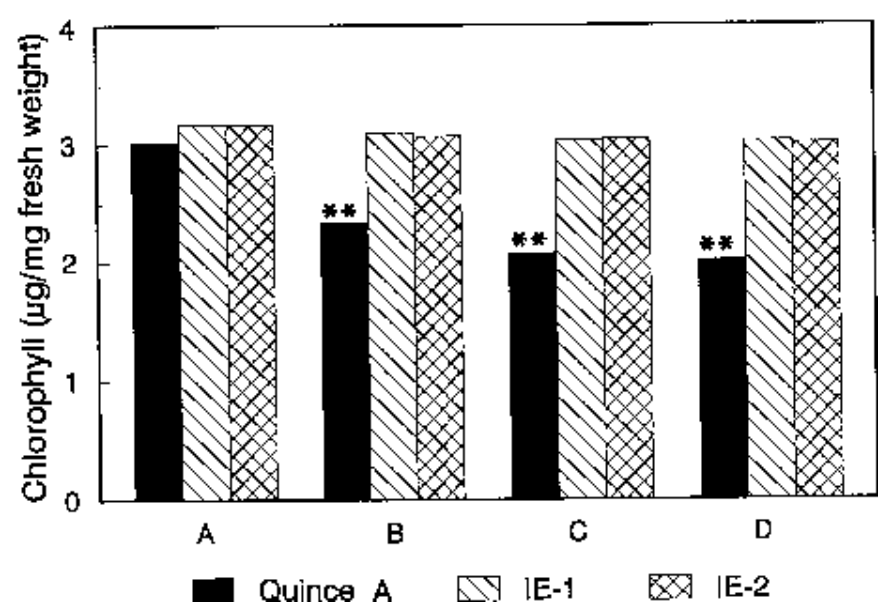

Fig. 1. Chlorophyll concentrations of the upper leaves of Quince A and somaclonal variants, IE-1 and IE-2, after 6 weeks of growth in control potting soil (A) and Fedeficient soil (B-D) (1993 experiment). **Highly significant difference between Quince A and the variants within a treatment.

experiment, with five soil treatments (A-E), was started on $15 \mathrm{Apr}$. A nested design was used, with four blocks of five rows each. Each row represented one soil type and contained six plants, two each of Quince A, IE-1, and IE-2, randomly arranged. For chlorophyll and $\mathrm{Fe}^{+2}$ determinations, each plant was considered an experimental unit. Leaf samples for chlorophyll determinations were collected on 15 June, 15 July, and 15 Aug. The upper three fully expanded leaves from a shoot of each plant were collected for chlorophyll extraction. Concentrations of $\mathrm{Fe}^{+2}$ were determined on the same samples on 15 Aug. The $\mathrm{pH}$ was measured on a random sample of each soil type.

For treatment $\mathrm{A}$, the standard greenhouse potting soil mixture (see above) was used and plants were watered (tap water) twice weekly. For treatment B, a mixture of 1 perlite : 1 soil collected from an orchard near Medford (southern Oregon), where trees showed symptoms of Fe-deficiency chlorosis, was used. Plants were watered once weekly with tap water and once weekly with one-quarter strength Hoagland solution (without Fe). For treatments C, D, and E, the same soil-perlite mix was used as for treatment $\mathrm{B}$, but lime (500 $\mathrm{mg}$ hydrate lime and $500 \mathrm{mg}$ dolomite lime $/ 50 \mathrm{~g}$ soil) was added to the medium. Plants for treatment $\mathrm{C}$ were watered as those of $\mathrm{B}$, while those for treatments $\mathrm{D}$ and $\mathrm{E}$ received one-quarter strength Hoagland solution containing $1 \mathrm{~mm}$ and $10 \mathrm{~mm} \mathrm{KHCO}_{3}$, respectively. Treatments A-D in 1993 and A$\mathrm{E}$ in 1994 were designed to increase Fe-deficiency stress in plants (Table 1). Saucers were placed under the pots to minimize loss of water or nutrients.

Field experiments. During Fall 1992, 15 acclimated plants each of Quince A, IE-1, and IE-2 were transferred from the greenhouse to a nursery plot in IRTA Reus, Spain. Plants were arranged in a completely randomized design with four blocks, each containing three to four plants of the three clones. The upper three fully expanded leaves from a shoot of each plant were collected for chlorophyll extraction on the following three dates: 27 May 1993, 18 May 1994, and 13 June 1994. Each plant was represented by one chlorophyll sample.

Chlorophyll measurements. Leaves were cut into pieces, weighed, and incubated in $N, N$-dimethylformamide (DMF) at $4{ }^{\circ} \mathrm{C}$ in the dark (Moran, 1982). The absorbance of extracts was determined at 647 and $664.5 \mathrm{~nm}$ using a UV-VIS spectrophotometer (model UV-1601; Shimadzu). The amount of chlorophyll was determined using the equation $17.90 \mathrm{~A}_{647}+8.08 \mathrm{~A}_{664.5}$ (Inskeep and Bloom, 1985) and expressed as $\mu \mathrm{g} \cdot \mathrm{mg}^{-1}$ leaf fresh weight.

Determination of $\mathrm{Fe}^{+2}$ concentration. The $\mathrm{Fe}^{+2}$ concentration of the upper leaves was determined following extraction with 2,2'bipyridyl (Abadia et al., 1984). Tissues were incubated on an orbital shaker in the dark for $24 \mathrm{~h}$. After passage through Whatman no. 1 filters, the absorption at $522 \mathrm{~nm}$ was determined. A standard curve was obtained with $\mathrm{Fe}^{+2} \mathrm{SO}_{4}$, reduced by treatment with hydroxylamine- $\mathrm{HCl}$. The $\mathrm{Fe}^{+2}$ concentration was expressed as $\mu \mathrm{g} \cdot \mathrm{g}^{-1}$ leaf fresh weight.

Data analyses. For the 1993 experiment (chlorophyll concentrations), comparisons were made between the genotypes within each soil type. The StatGraphics program was used to determine significance of differences between clones within each treatment. The 1994 experiment was set up as a split-plot design with soil treatments as the main plot, clones as the subplot, and dates as the sub-subplot. Data were analyzed with the SIPS program (Oregon State Univ.). For the field experiment, comparisons were made between clones for each date of analysis with the StatGraphics program.

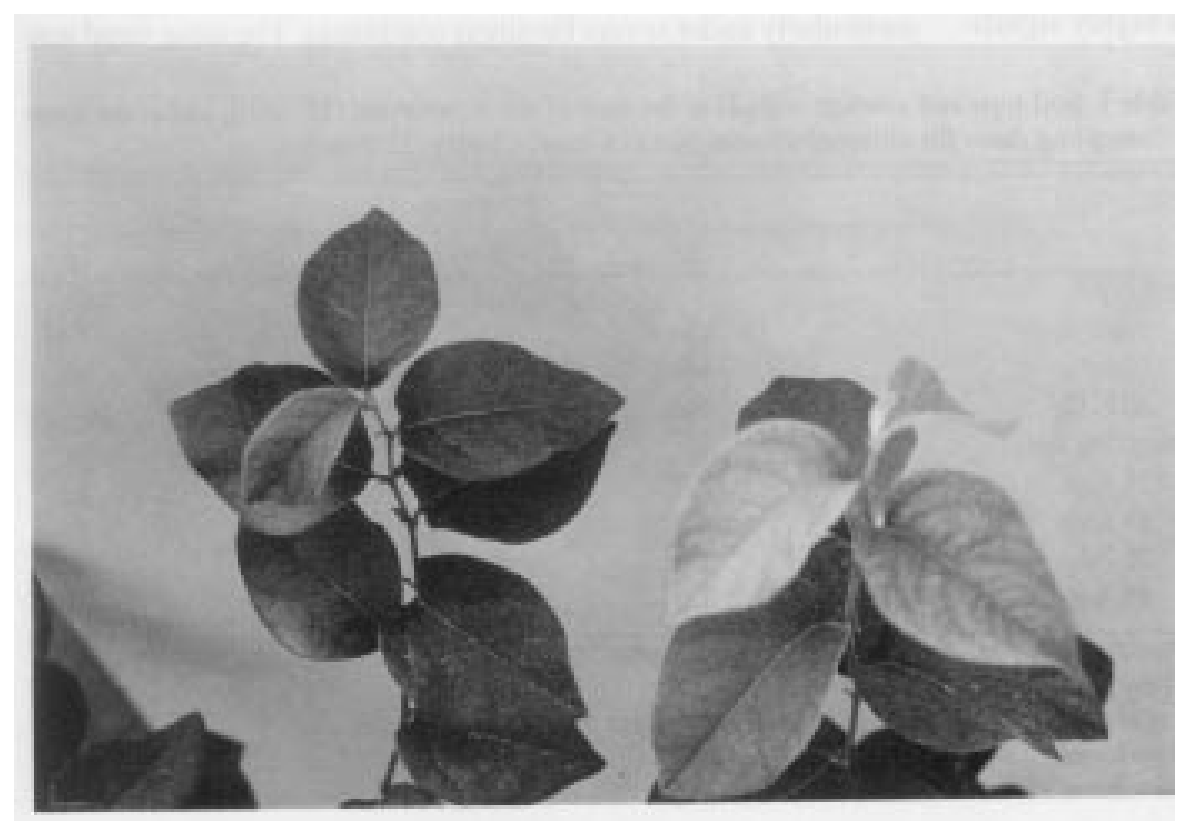

\section{Results}

Differences in leaf color were observed between the original Quince A clone and the two variants in the greenhouse in 1993. Newly developing leaves of Quince A were chlorotic after 4 weeks of growth in high-pH soils (treatments B-D), whereas leaves of variants remained green. Measurements of leaf chlorophyll concentrations supported the visual observation (Fig. 1). Although the design of the experiment did not allow comparisons between soil treatments, there were highly significant clonal differences $(p<0.001)$ within each of the three treatments using high-pH soil (B, C, and D). The differences were due to the lower chlorophyll concentrations in the original clone; the two variants did not differ from

Fig. 2. Plant of IE-2 (left) and Quince A (right) after 3 months of growth in soil D. 
each other. Also, there was no difference $(p=0.44)$ between the clones on soil A.

A clear contrast was observed between the greenhouse performance of variants and Quince A in 1994 (Figs. 2 and 3). Under all high-pH treatments, variants remained greener than Quince A. The chlorophyll concentration in Quince A leaves decreased with the severity of Fe deficiency caused by the high $\mathrm{pH}$ of the soil and increasing bicarbonate level in the treatments. It should be noted that the $\mathrm{pH}$ of the soils remained rather stable during the experiment (Table 1). Highly significant interactions between all factors were detected (Table 2). The interactions can be partially explained by the rapid decrease in chlorophyll concentration of Quince A early in the experiment, while the decrease in the variants occurred mainly between 15 July and 15 Aug. (Fig. 3). The magnitude of differences between the variants and the original clone decreased with time for the high $\mathrm{pH}$-bicarbonate treatments (Fig. 3). Even though the interactions were highly significant, the mean square for clones was much higher than that for the interactions (Table 2). Interactions were the result of changes in the magnitude of clonal differences rather than an absence of significant differences for some treatments.

A comparison of the $\mathrm{Fe}^{+2}$ concentrations in the leaves showed that, as expected, the $\mathrm{Fe}^{+2}$ decreased with increasing lime (and $\mathrm{pH}$ ) of the soil (Fig. 4). There were highly significant interactions between soil and clone, as was the case with chlorophyll concentrations. However, the patterns of $\mathrm{Fe}^{+2}$ were somewhat different from the chlorophyll contents. The variants differed from the Quince A control under all conditions and had particularly high $\mathrm{Fe}^{+2}$ in normal potting soil, indicating that they may have higher $\mathrm{Fe}(\mathrm{III})$-reducing and Fe-uptake ability, even under conditions where Fe is readily available to the plant. Moreover, there were differences between the two variants under treatments A, C, and D, with higher Fe $\mathrm{Fe}^{+2}$ concentrations in IE-2 than IE-1 (Fig. 4). These differences, however, were not reflected in differences in chlorophyll content (Fig. 3c).

The variants were evaluated for changes in morphology or growth patterns. No visible differences were noted between the variants and Quince A at any time, except for leaf color.

In evaluations performed in the field in 1993, IE-1 and IE-2 were greener than the Quince A control. The nursery at IRTA Reus has a high soil $\mathrm{pH}(8.6)$ and high carbonate content $(10.6 \%$; w/w), which should limit Fe availability. The difference in the chlorophyll concentrations between the three clones was highly significant $(p=0.0002)$ (Table 3$)$. However, in 1994, the variants did not differ from the control on 18 May, and only IE-1 had a significantly higher chlorophyll concentration than the control on 13 June (Table 3). Thus, the differences between the clones seem to vary between sampling times.

\section{Discussion}

In our previous study (Dolcet-Sanjuan et al., 1992), the two somaclonal variants of Quince A exhibited improved efficiency in Fe utilization in vitro based on chlorophyll concentration, $\mathrm{Fe}^{+2}$ content, $\mathrm{Fe}(\mathrm{III})$ reduction by roots, and acidification of the culture medium. Because phenotypic reversal of somaclonal variants can occur over time or due to a change in the environment (Karp, 1995), greenhouse and field studies were experiment.

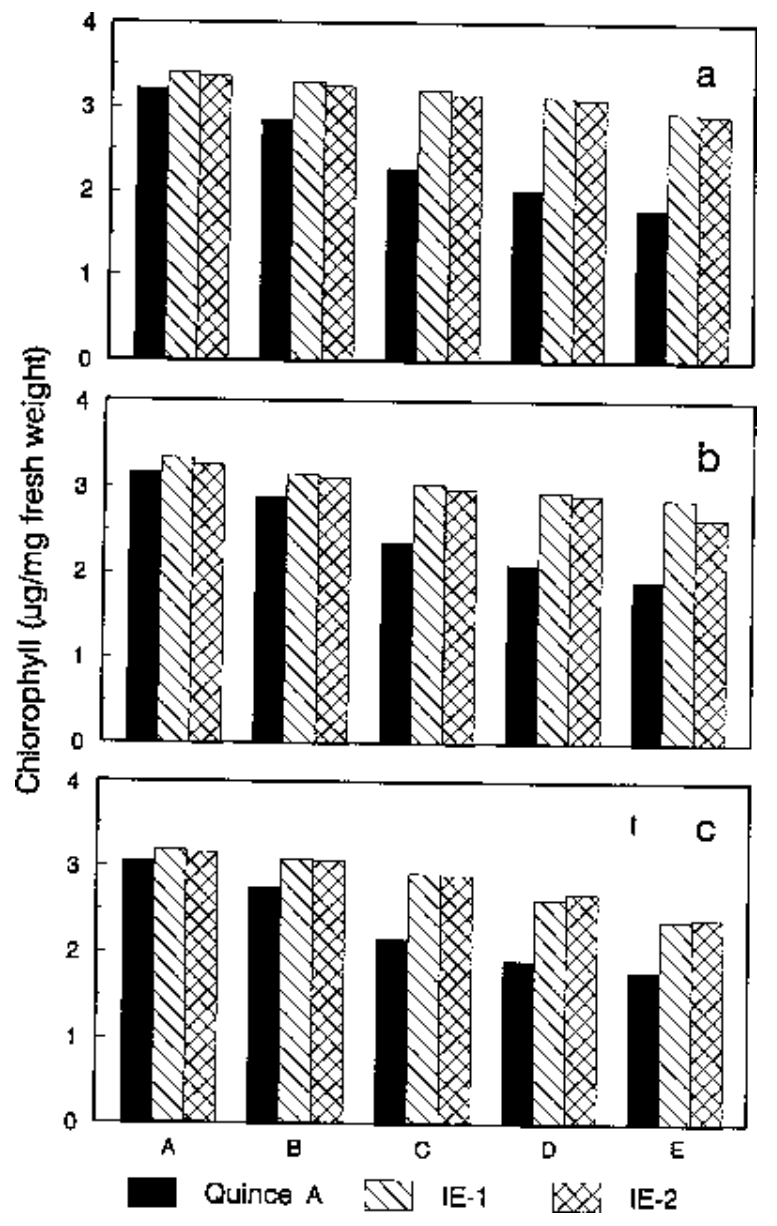

Fig. 3. Chlorophyll concentrations of the upper leaves of Quince A and two somaclonal variants, IE-1 and IE-2, in control potting soil (A) and Fe-deficient soil (B-D) on 15 June (a), 15 July (b), and 15 Aug. (c) (1994 experiment). The bar denotes the LSD $(0.05)$ for the entire experiment.

conducted to determine stability and economic potential of these variants. In greenhouse experiments, using potting mixtures of $\mathrm{Fe}$ deficient soil from southern Oregon, differences in chlorophyll concentrations were observed between the variants and Quince A, particularly under severe Fe-stress conditions. The same trend was

Table 1. Soil type and average soil $\mathrm{pH}$ at the start of the experiment (15 Apr.), and at the three sampling dates for chlorophyll analyses (15 June, 15 July, 15 Aug.).

\begin{tabular}{lccccc}
\hline & \multicolumn{5}{c}{ Treatment } \\
\cline { 2 - 6 } & $\mathrm{A}$ & $\mathrm{B}$ & $\mathrm{C}$ & $\mathrm{D}$ & $\mathrm{E}$ \\
\hline Soil type & & & Soil conditions & & \\
Field soil & $\mathrm{No}^{\mathrm{z}}$ & Yes & Yes & Yes & Yes \\
Lime $^{\mathrm{y}}$ & $\mathrm{No}$ & No & Yes & Yes & Yes \\
KHCO $_{3}{ }^{\mathrm{x}}$ & No & No & No & $1 \mathrm{mM}$ & $10 \mathrm{mM}$ \\
Sampling date & & & $p H$ & & \\
15 Apr. & 5.0 & 7.3 & 8.3 & 8.3 & 8.3 \\
15 June & 4.8 & 7.2 & 8.1 & 8.1 & 8.1 \\
15 July & 4.6 & 7.0 & 8.0 & 8.0 & 8.0 \\
15 Aug. & 4.6 & 7.0 & 8.0 & 8.0 & 8.0 \\
\hline
\end{tabular}

${ }^{\mathrm{z}}$ Potting soil, consisting of a mixture of 2 peat : 1 perlite : 1 vermiculite and Nutricote slowrelease fertilizer $\left(2 \mathrm{~kg} \cdot \mathrm{m}^{-2}\right)$.

${ }^{y}$ Lime $(500 \mathrm{mg}$ hydrate and $500 \mathrm{mg}$ dolomite lime $/ 50 \mathrm{~g}$ soil) was added to soil at start of

${ }^{\mathrm{x}}$ Given weekly in solution. 
Table 2. Analysis of variance of chlorophyll concentration in leaves as influenced by soil, genotype, and sampling date (1994 experiment).

\begin{tabular}{lrcc}
\hline \hline Treatment & df & Mean square & $P$ \\
\hline Block & 3 & 0.0339 & 0.43 \\
Soil (S) & 4 & 7.9782 & $<0.0001$ \\
Error (a) & 12 & 0.0342 & \\
Clone (C) & 2 & 13.9370 & 0.0004 \\
$\mathrm{~S} \times \mathrm{C}$ & 8 & 0.9421 & $<0.0001$ \\
Error (b) & 87 & 0.0180 & \\
Date (D) & 2 & 1.9721 & $<0.0001$ \\
$\mathrm{D} \times \mathrm{S}$ & 8 & 0.0737 & $<0.0001$ \\
$\mathrm{D} \times \mathrm{C}$ & 4 & 0.2229 & $<0.0001$ \\
$\mathrm{D} \times \mathrm{S} \times \mathrm{C}$ & 16 & 0.0395 & 0.001 \\
Error $(\mathrm{c})$ & 90 & 0.0140 & \\
Sampling error & 180 & 0.0228 & \\
\hline
\end{tabular}

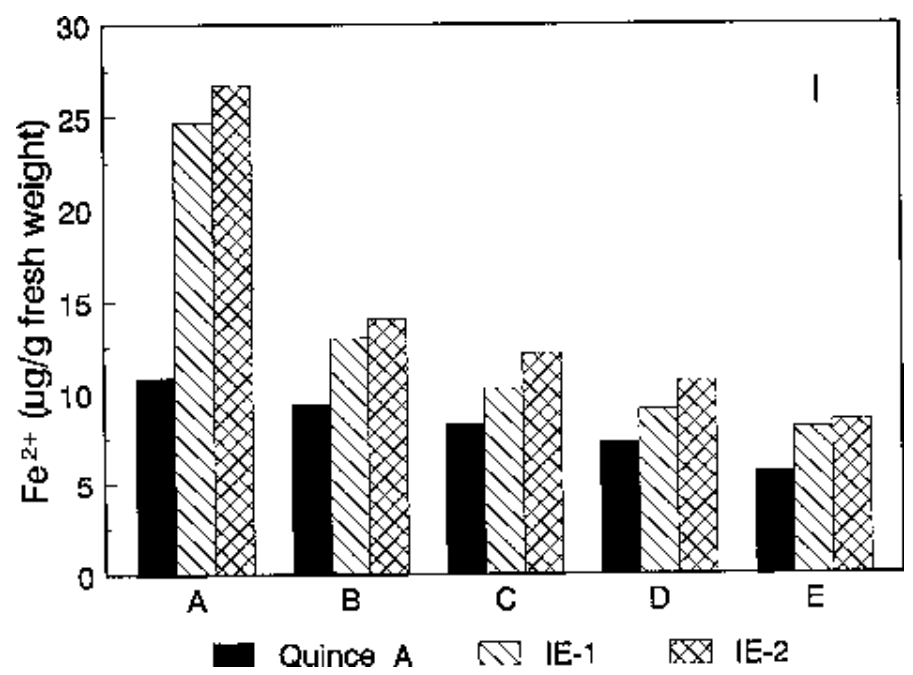

Fig. 4. $\mathrm{Fe}^{+2}$ concentrations of the upper leaves of Quince A and two somaclonal variants, IE-1 and IE-2, in control potting soil (A) and Fe-deficient soil (B-E) on 15 Aug. (1994 experiment). The bar denotes the LSD (0.05).

observed for $\mathrm{Fe}^{+2}$ concentrations. In Quince $\mathrm{A}$, the $\mathrm{Fe}^{+2}$ decreased with increasing $\mathrm{Fe}$ stress due to an increase in $\mathrm{pH}$ and bicarbonate concentration. Although a similar pattern was observed in the somaclonal variants, the $\mathrm{Fe}^{+2}$ concentration was always higher in the variants than in Quince A at the same $\mathrm{pH}$. These findings indicated that the high Fe efficiency of the variants detected in vitro (Dolcet-Sanjuan et al., 1992) was maintained under greenhouse conditions.

Field trials are currently being performed at two sites: southern Oregon and IRTA Reus. The latter site has been chosen partly because of its elevated bicarbonate levels and high $\mathrm{pH}$, representative of Fe-deficiency stress conditions present in the Mediterra-

Table 3. Chlorophyll concentrations of the upper leaves of Quince A, IE1 , and IE-2 under Fe-deficiency stress conditions in the nursery at IRTA Reus, Spain.

\begin{tabular}{lccc}
\hline & 27 May 1993 & 18 May 1994 & 13 June 1994 \\
\hline Quince A & $1.09 \mathrm{a}^{\mathrm{z}}$ & $1.40 \mathrm{ab}$ & $0.81 \mathrm{a}$ \\
IE-1 & $1.30 \mathrm{~b}$ & $1.48 \mathrm{~b}$ & $1.17 \mathrm{~b}$ \\
IE-2 & $1.40 \mathrm{~b}$ & $1.36 \mathrm{a}$ & $1.04 \mathrm{ab}$
\end{tabular}

${ }^{\mathrm{z}}$ Means within columns followed by the same letter are not different $(P=$ 0.05) according to Fisher's protected LSD. nean region. Although data are still limited, preliminary results indicate that differences between the variants and Quince A are not as wide and as consistent as found in the greenhouse study. Chlorophyll concentrations of the leaves in the field are generally lower than those found under severe stress conditions in the greenhouse, for variants as well as Quince A, indicating that the conditions at IRTA Reus are quite severe. Moreover, since no Fe has been supplied to the field at any time, the stress is exerted over a longer period. The data also suggest that the variants may not be able to overcome the adverse conditions at this site and that adding $\mathrm{Fe}$ chelate is required.

A host of events, including aberrant chromosome numbers and structure, point mutations, amplification, and methylation, can lead to somaclonal variation (Kaeppler and Phillips, 1993; Lee and Phillips, 1988); of these, amplification and methylation, as well as other epigenetic variation, are potentially reversible. Heritability of this trait and the molecular genetic basis for the variation have not yet been determined. However, the Fe efficiency of the quince variants has been maintained for more than 5 years in the absence of selection. Although progeny tests are generally most definitive, they may not be practical for vegetatively propagated crops with a very long generation span and high heterozygosity. Phenotypic stability over time and through propagation may be sufficient criteria for selecting clones of such crops.

As far as we know, this is the first study involving selection for Fe efficiency in vitro and the only study of quince variants derived from tissue culture. However, several other interesting somaclonal variants have been reported for fruit trees belonging to the Rosaceae family (Hammerschlag, 1992). For instance, peach regenerants with increased bacterial leaf spot resistance have been obtained (Hammerschlag, 1990), some of which have maintained their resistance through greenhouse and field tests (Hammerschlag et al., 1994). Variants of apple with increased fireblight resistance have been identified in vitro and in the greenhouse (Donovan et al., 1994). Somaclonal variants exhibiting resistance to fireblight have also been reported for pear; however, the two identified somaclones also have twice the normal chromosome number along with altered morphological traits, which may contribute to fireblight resistance (Viseur and Tapia y Figueroa, 1987). Selection of sour cherry for salt tolerance has resulted in recovery of variants with increased tolerance (Ochatt and Power, 1989). These and other studies (Hammerschlag, 1992) demonstrate that plants regenerated from tissue culture may contribute valuable variation to fruit tree germplasm.

It will be of interest to extend Fe-efficiency observations to a range of soil types representing different degrees of Fe stress to evaluate the inherent advantage of the variants. The soils in some of the orchards in southern Oregon may provide milder conditions than those in IRTA Reus. Trials will be conducted with these rootstocks in combinations with pear cultivars as scion to determine their potential for commercial pear production.

\section{Literature Cited}

Abadia, J., E. Monge, L. Montanes, and L. Heras. 1984. Extraction of iron from plant leaves by Fe II chelators. J. Plant Nutr. 7:777-784.

Dolcet-Sanjuan, R. 1991. Somatic manipulation of Pyrus and Cydonia: Characterization and selection for iron efficiency. $\mathrm{PhD}$ diss., Oregon State Univ., Corvallis.

Dolcet-Sanjuan, R., D.W.S. Mok, and M.C. Mok. 1990. Micropropagation of Pyrus and Cydonia and their responses to Fe-limiting conditions. Plant Cell Tiss. Org. Cult. 21:191-199.

Dolcet-Sanjuan, R., D.W.S. Mok, and M.C. Mok. 1992. Characterization and in vitro selection for iron efficiency in Pyrus and Cydonia. In Vitro 
Cell. Dev. Biol. 28:25-29.

Donovan, A.M., R. Morgan, C. Valobra-Piagnani, M.S. Ridout, D.J. James, and C.M.E. Garrett. 1994. Assessment of somaclonal variation in apple. I. Resistance to the fire blight pathogen, Erwinia amylovora. J. Hort. Sci. 69:105-113.

Hammerschlag, F.A. 1990. Resistance responses of plants regenerated from peach callus cultures to Xanthomonas campestris pv. pruni. J. Amer. Soc. Hort. Sci. 115:1034-1037.

Hammerschlag, F.A. 1992. Somaclonal variation, p. 35-55. In: F.A. Hammerschlag and R.E. Litz (eds.). Biotechnology of perennial fruit crops. C.A.B. Intl., Wallingford.

Hammerschlag, F.A., D.J. Werner, and D.F. Ritchie. 1994. Stability of bacterial leaf spot resistance in peach regenerants under in vitro, greenhouse and field conditions. Euphytica 76:101-106.

Inskeep, W.P. and P.R. Bloom. 1985. Extinction coefficients of chlorophyll $\mathrm{a}$ and $\mathrm{b}$ in N,N-dimethylformamide and $80 \%$ acetone. Plant Physiol. 77:483-485.

Kaeppler, S.M. and R.L. Phillips. 1993. DNA methylation and tissue culture-induced variation in plants. In Vitro Cell. Dev. Biol. 29P:125-130.

Karp, A. 1995. Somaclonal variation as a tool for crop improvement. Euphytica 85:295-302.

Lee, M. and R.L. Phillips. 1988. The chromosomal basis of somaclonal variation. Annu. Rev. Plant Physiol. Plant Mol. Biol. 39:413-437.

Lombard, P.B. and M.N. Westwood. 1987. Pear rootstocks, p. 145-183. In: R.C. Rom and R.F. Carlson (eds.). Rootstocks for fruit crops. Wiley, New York.

Moran, R. 1982. Formulae for determination of chlorophyllous pigments extracted with N,N-dimethylformamide. Plant Physiol. 69:1376-1381.

Ochatt, S.J. and J.P. Power. 1989. Selection for salt-drought tolerance using protoplast- and explant-derived tissue cultures of Colt cherry (Prunus avium $\mathrm{x}$ pseudocerasus). Tree Physiol. 5:259-266.

Viseur, M.J. and M. Tapia y Figueroa. 1987. In vitro co-culture as a tool for the evaluation of fireblight resistance in pears and apples. Acta Hort. 217:273-282.

Viti, R. and F. Cinelli. 1989. Evaluation of some clonal quince rootstocks in calcareous soil. Acta Hort. 256:53-61. 